\title{
Learning to build sustainable communities: an interdependency network perspective
}

\author{
John Lever* \\ Huddersfield University Business School \\ Ian Smith \\ University of the West of England
}

\begin{abstract}
This paper explores the production of sustainable communities from an interdependency network perspective (Newton, 2001). Drawing on fieldwork that examined how planners worked collaboratively with other professionals to address the challenges of delivering New Labour's Growth Point Initiative, the paper fuses insights from Actor Network Theory with Figurational Sociology to examine the requirements of the skills agenda for building sustainable communities (ODPM, 2004). Through an exploration of the ways in which planners adapted their working practice to facilitate the dual task of delivering growth and sustainable development, we argue that the learning and skills agenda is problematic for understanding how new knowledge and learning emerges.
\end{abstract}

Keywords: interdependency network; networked agency; knowledge; learning; sustainable communities.

\section{Introduction}

Over the last decade there has been much policy and academic interest in the skills, learning and knowledge needed to build and achieve sustainable communities (ODPM, 2003; Egan, 2004; ASC, 2007). The Egan Review (2004) identified planners, built environment practitioners and a range of other professionals as 'core occupations' for the challenges presented by the demand for sustainable communities (ODPM, 2003). First, it was argued that the challenges of building sustainable communities cut across geographic, organisational and social boundaries and that appropriate solutions require a blend of past experience and new forms of collaborative, partnership working. Second, in a wide-ranging critique of the planning system, the review argued that new skills and knowledge were needed in the public sector if private sector investment was not to be 'squandered'. 
This paper draws on empirical material from a project funded through a targeted programme of research - jointly funded by the ESRC and the Academy for Sustainable Communities (ASC) ${ }^{1}$ - that set out to explore the skills and knowledge needed to build and develop sustainable communities. ${ }^{2}$ In 2006, the New Labour Government (DCLG, 2008) awarded 20 areas in Southern England and the Midlands New Growth Point (NGP) status. Our project set out to examine how planners involved in the development of an NGP in southern England worked collaboratively to address the challenges involved. The basic proposition of the research was that the capacity of individual practitioners to learn and adapt their practice is not just linked to the availability of knowledge and skills, but also to the social context in which practice is embedded (Marsden, 2010). The project thus set out to find evidence for 'new' forms of practice. The methodology encompassed multiple methods, including face-to-face interviews, a telephone survey, on-line discussion groups, an e-mail survey and a workshop with key participants (see Smith, 2008; 2009). This paper only draws on material from the faceto-face interviews and the on-line discussion groups. ${ }^{3}$

The paper presents an account of the everyday, collaborative work of planners in order to build on insights into the complex institutional contexts in which they operate (Tait, 2002; Crawford, 2009; Sehested, 2009; Inch, 2010). Drawing on Newton (2001), we examine how learning emerges, not through the acquisition of individual skills and knowledge, but within complex networks of interdependency. Following Newton closely, we claim that an interdependency network perspective (INP) seriously questions the view of the 'independent' actor as the focus of learning by focusing on the ways in which 'outcomes', i.e. learning, reflect 'networked' forms of 'agency'. We proceed in the following way. In the first section, we explore the theoretical underpinnings of the paper. This is followed by an examination of developments in spatial planning and the implications for NGP work. We then explore the new ways of working that emerged on our NGP case study and how planners worked in a more flexible and strategic way to push forward the dual task of facilitating growth and sustainable development. In the final section, we provide an account of how networked forms of agency both enable and constrain growth and sustainable development in very particular ways. Rather than focussing on the acquisition of new knowledge and skills by individual practitioners, we conclude that it may be more productive to research the minimal levels of interdependency needed to support learning and the development of new knowledge.

\section{Theoretical development}

Fusing insights from Actor Network Theory (ANT) (Callon, 1986; 1986a; 1991) with Figurational Sociology (Elias, 1970; 1983; 1991; 2000), Newton (2001; see also 2007) outlines what he calls an Interdependency Network Perspective (INP). Actor Network Theory starts from the assumption that relations between entities are fundamental to understanding action. It asks how and for what purposes 'heterogeneous associations' of human and non-human actors are brought together and enrolled in networks (Callon, 1991) - enrolment is the means by which competing actors are bought together and converge in networks through the use of 'intermediaries' such as texts, machines, technical artefacts, money, skills and knowledge (Callon, 1991). The strength of ANT lies in its ability to give non-human agency a place in social analysis, yet the approach has been criticised because 'actors' are hard to pin down (see Newton, 2001). The term 'actor' is sometimes used to show that an agent is the primary 'author' of actions within a network, while intermediaries are often seen to be the links that bind networks together. Newton (1996) claims that the best way to overcome these difficulties is to view all actors as intermediaries rather 
than authors, as links in chains that both define and connect the relations between non-human and human forces.

Whilst recognising the strengths of ANT, Murdoch (2001: 129) argues that when 'the social causes of a given phenomenon are decisive' we should give them priority. Engestrom (2001: 140) claims likewise that ANT overlooks the internal properties and contradictions of learning within networks, and that we must be able to understand how these dynamics can 'energize a serious learning effort' in various institutional contexts. It is here that Figurational Sociology comes into its own, providing a way of examining the internal properties and contradictions within interdependency networks. While ANT writers focus on heterogeneous networks of human and non-human actors, figurational sociologists focus on networks (figurations) of interdependent human actors (Elias, 1970; 1983; 1991; 2000).

On this account, individuals can never be considered outside the networks of interdependency relations they form with each other. This means that the actions they take, the personalities they develop, and the ways of working that emerge within particular institutional settings are always dependent on networked forms of agency. Since intentions are always moderated by the interests of other networked groups, each with their own unique plans, objectives and intentions, it is often very difficult for individuals to determine absolute outcomes. Elias (1970; 1983; 1991; 2000) demonstrates throughout his work that the position of an established group is strengthened not simply because of an accumulation of power, but because of an increase in the number of coordinated positions within a figuration. It follows that power can be equated with control over the social and natural environment and with the attempts of competing groups to control this relationship. It also means that power relations within interdependency networks 'can work themselves out in ways that serve to constrain, as well as enable, learning' (Owen-Pugh, 2007, 90). As for Vygotsky (1978), knowledge emerges as a cultural process of learning and socialisation within a given context through the use of shared symbols and language (Elias, 1991).

The relevance of these arguments become clear if we consider the development of our case study NGP in southern England, where human and non-human forces converging around particular industries constrain and enable growth and sustainable development in very particular ways. However, before moving on to look at the impact of the new ways of working that emerged around our case study NGP project, we now briefly examine the emergence of the spatial planning agenda, as it is this approach that has given planners the space and opportunity to engage in new networked activities.

\section{Spatial planning, growth and sustainable development}

There were two main thrusts of government policy in England through the 2000s that put built environment professionals (including but not exclusively planners) in a position where they had to reformulate their practice and understanding of producing the built environment. From 2001 to 2010, New Labour set themselves the complex task of reforming the statutory English planning system as a vehicle for integrating the spatial development outcomes of public (national and local) policy (Cullingworth and Nadin, 2006; Inch, 2010). In line with a wider modernisation agenda (Newman, 2001), this change was promoted by New Labour as a fundamental break with the past (DTLR, 2001) that would allow planners to take on a more proactive and dynamic role (Cullingworth and Nadin, 2006; Tewdwr-Jones, 2004). Throughout this period, planners were expected to seek integrated policy responses with a wider range of policy stakeholders than had previously been the explicit case. As they reformed the statutory 
planning system, New Labour also attempted to promote house building and new building technologies that would contribute to a broader set of desirable sustainability outcomes whilst facilitating growth. New Growth Point Projects (NGPs) emerged as demonstrator projects to show how growth and sustainable development could be delivered simultaneously through the production of new built environments.

New Growth Point projects were tasked with producing many thousands of homes, workplaces and ancillary developments (infrastructure, amenities and services) needed to support new communities in ways that were sustainable and framed their low impact trajectory into the future. The scale and complexity of this task had been largely absent from the work of planners since the New Towns Initiatives of the 1950s and '60s. The new projects - which were to be implemented over relatively long time periods (5-15 years) - were required to deliver large numbers of housing units (5-30,000 per project) and coordinate a large number of multi-use, multiple area and multi-phase components. These characteristics meant that some of the pre-2001 distinctions between plan-making and reviewing development applications in planning practice were blurred where NGP projects were being implemented (Smith, 2008; 2009).

This paper explores these tensions as they emerged during negotiations to decide whether an NGP project was going to be permitted in a local planning authority in southern England. The negotiations were conducted to define what the developer for the housing component of the NGP project needed to pay as a contribution for infrastructure (mainly roads) and the provision of public services (such as schools) to ensure that the new development did not impose an unreasonable impact on existing residents; making development proposals acceptable in planning terms is known as a Section 106 agreement. Stakeholders representing highways, recreational services, education, health, environment and housing are all part of such negotiations. The case study NGP project consisted of various elements, including a range of employment land uses and transport facilities and a community of new and 'sustainable' housing. Negotiations on the Section 106 agreement were thus particularly complex. There were considerations over social and community infrastructure, transport and the future proofing of infrastructure, for example, as well as affordable housing, sustainable construction and alternative energy supplies. In what follows we examine the informal processes of these negotiations in order to explore how practitioners adapted their practice to address the challenges involved (Smith, 2008; 2009).

\section{The NGP and new ways of working}

The NGP case study project received the designation of a new growth point in October 2006 (DCLG, 2007; 2008). Supported by a County Council and two District authorities, the process formalised a series of development projects into a single NGP project combining housing, employment land uses and infrastructure development. A coalition of developers interested in promoting the project (principally a housing development for up to 2,900 houses, but including schools, employment and shopping facilities and infrastructure development) started putting together an outline planning application in 2003, which was granted subject to the Section 106 agreement in December 2006.

Throughout a period of collaborative activity (which crossed administrative boundaries between districts, between tiers and between different agencies, consultees and service providers) research participants claimed that the new aspect of working on NGPs was about having the time and space to look at problems more widely, thus enabling the development of appropriate solutions in the face of rapid technological and policy change. In the period up to October 2006, planners within the district authority and partners (including County Council strategic planners) had worked 
on different formulations that would combine the different components of the sustainable urban extension (i.e. housing, employment uses, airport expansion and infrastructure development) within a feasible financial package. The Section 106 agreement negotiations started in May 2005 and were on-going at the time of the planning decision in December 2006.

During discussions facilitated by planners in the District authority, there was a gradual recognition of the value of a collaborative approach, yet for a long time it was still very difficult to encourage joined up responses to the challenges that were emerging. It soon became clear that planners had to work in a much more flexible and strategic way if they were to move the NGP agenda forward (Crawford, 2009; Smith, 2008, 2009; Karadimitriou, 2013). Some respondents emphasised the need for flexibility as a way of getting people to think about sustainability pragmatically, rather than just seeing things from their own perspective. As a transport planner at the district level pointed out:

There's no point having a specialist that just wants public transport, or just wants cycling routes, or just wants a school. That person needs to understand ... how schools relate into transport and how they relate into design... a broad understanding of all the different links.

Although it was recognised that planners have always had to consider a wide range of issues in their work, there was a feeling that this part of the job was intensifying. A district town planner argued that planners now have to know about:

Absolutely everything! The way houses are built, how they're built, renewable energy, how you put green roofs on buildings, how much it costs to put a green roof on a building, rain water recycling, climate change, everything.

The greater specialisation and complexity needed to negotiate planning agreements resulting from the increased focus on sustainable development and new technology was significant. By increasing interdependencies between diverse professional groups with differing philosophical standpoints, the foundations for future collaborative work and social learning were strengthened. In the early stages of the research, a number of sustainability consultants finding their way in this new collaborative environment registered for our on-line forums. They explained their participation not simply in terms of an opportunity to influence decision making, but to 'get up to speed' on the views and positions of other networked groups.

Planners also argued that they are also coming under greater pressure to play a more proactive role than they have done previously. The prime function of Development Control Planners - to determine planning applications in accordance with planning legislation - has always been something that is learnt on the job, through practice, but it was widely argued that those employed in this capacity now have to work more open and flexibly if they are to avoid problems further down the line. This was directly relevant to negotiations on the Section 106 agreement. Many research participants argued that the speed of technological change and associated changes in priorities means that it is often difficult to pin things down at the outset and that things now often have to be renegotiated.

In this context, it appeared that a major skill involved the ability to balance different objectives strategically within a long-term vision. Rather than looking at a map and saying 'this area is good for housing' and colouring it blue, and saying that 'we need a recreation ground here' and colouring it red, it was argued that planners now need to be much more open if they are to get these things right over the long term. As a member of the strategy team at the County Council pointed out: 
The whole kind of... growth point thing is about creating a sustainable community so it's about doing much more than that. So it's working out how the infrastructure then links together and it's about understanding how one site then relates to another and how you can bring sort of common goals together through a number of sites.

Throughout the project we encountered many tensions between established groups (Elias, 2000) and new ways of working (see Inch, 2010). At the strategic (County) level, where there was a strong drive to implement spatial planning and the knowledge and skills agenda as quickly as possible, there was also a feeling that many of the problems planners encounter on Section 106 negotiations could be overcome by addressing the prevailing 'culture of minor negotiations'. The implication here was that individual planners from different directorates found it difficult to collaborate and that they often retreated to a 'mine's the most important issue' position, particularly when the going got tough.

Spatial planning is concerned with "the problem of coordination or integration of the spatial dimension of sectoral policies through a territorially-based strategy' (Cullingworth and Nadin, 2006: 91). In line with these changes, a participant in an online forum argued that Development Control Planning (DCP) should become part of a more general planning function and that it would be better to think in terms of strategy, policy, delivery and monitoring teams instead. This was highly controversial. While some planners agreed that 'the devil is in the detail' of Section 106 negotiations for DCP, others countered that such problems only emerge when developers force an issue and planners retreat to their own directorates. As a planner at the County Council pointed out:

Without doubt as the detail [on the Section 106 agreement] unfolds the developer argues that there 'isn't anything left' and the smaller investment elements, youth, libraries, early years and to some extent schools gets squeezed by the demands on the big infrastructure parties ... [such as] ... Highways.

This quote illustrates the centrality of power relations in determining outcomes within interdependency networks. While new technologies are being introduced in different ways by different agencies at different levels to address the challenge of sustainability, power relations between the smaller groups pursuing sustainability initiatives and the larger infrastructure parties linked to older technologies present significant barriers to change.

\section{Prioritising individual action and agency}

The story of negotiating the shape and form of the NGP project through outline planning permission and the Section 106 agreement also elicited views from planners about the knowledge they had and the knowledge they needed to move the NGP forward. Much of this discussion emphasised the role of the individual practitioner in the delivery process, as well as the institutional context within which change was taking place. While much of the policy and governance literature emphasised the interconnected nature of responsibility on the building of NGPs and sustainable communities, discussions around the acquisition of new knowledge and skills simultaneously stressed the role of individual actors in acquiring new skills and knowledge (ODPM, 2003; Egan, 2004; ASC, 2007). This significantly overlooks, we argue, the networks within which knowledge emerges.

As the research progressed, the problematic nature of assuming that individuals are the principal agents of change grew in significance. Through discussions initiated in the 
on-line forums it soon became clear that many planners working in this context had little time to reflect on what they do and make appropriate changes in practice. While they could ask questions and problematise the building of a NGP from their own perspective, they had little time to move on to stabilise the role of other actors and enrol and mobilise them in line with their objectives (Callon, 1991). As a planner from the District authority explained:

[O]ne of the frustrating things about our job is we never have enough time to review what's been done and for everybody to accept there's a special way of doing it and to move on "cause the same mistakes are frequently made again and again.

Unable to identify time to think about what they do through deliberative reflection (Eraut, 2004), many planners spoke of moments of realisation - what Eraut and Hirsh (2010) refers to as reactive or intuitive learning.

Participants in the on-line discussion forums talked about 'eureka' moments when they suddenly realised a key issue or insight that allowed them to move forward. Asked about 'eureka' moments one planner suggested conversely that: 'In my experience it is usually more of a ' $d$ 'oh' experience than a 'eureka' one'. Although these moments were important, it was clear that they did not always emerge at work. They sometimes occurred on the drive into work, for example, which meant that an important insight or reflection was lost or forgotten during the intensity and complexity of the working day. Developing new skills and knowledge in this context was thus highly problematic.

\section{Culture change}

The fear that established groups of planners will act as barriers to the implementation of spatial planning has been well discussed (e.g. DCLG, 2008; Richards, 2007; RTPI, 2007; Tewdwr-Jones, 2004). Viewed from this perspective, the knowledge and skills agenda can be viewed as an example of a cultural change programme that attempts to change individual practice by opening the door to more flexible and strategic working (Newton, 2001; Inch, 2010; Marsden et al., 2010). As Inch $(2010,360)$ confirms, the 'idea of a culture change suggests that the existing culture of English planning is, in some way, a problem and that planners are out of step with the requirements of spatial planning'.

Much has been made of empowerment in this context and of the need to give public sector workers more freedom to operate (Newman, 2001). By increasing the operational scope of public sector workers in this way there is an assumption that those involved in collaborative activities will transform the way they work and act as agents of change (Lever, 2011). Although influential, the approach has also been widely criticised. Raco (2005), for example, argues that New Labour prioritised private sector involvement in the decision-making process over and above sustainable development in order to realise the benefits of private sector investment.

A district planner picked up on this in a discussion of the problems planners face in their negotiations with developers on large NGP type projects:

When we talk about negotiation skills it's almost a bit like sort of poker playing, bluffing and let's see what we can go for. Let's not tell them what the bottom line is. There are all those kind of things and [people need to have the] confidence to do that.

As complexity and specialisation increase, planners often find themselves in conflict over professional competences in one context and partners in negotiations in another. Elias (2000: 318) argues that this 'fundamental ambivalence of interests is one of the 
most structural characteristics of more highly developed societies.' For it is this latent ambivalence, he argues, within which individual actions are both 'adjusted to and contrary to each other' (Elias, 2000: 322) that molds civilised conduct and furthers social learning.

Through discussions initiated in on-line forums it often appeared that the objections many planners had to new ways of working were philosophical rather than practical. Some planners argued that they did not want planning to become part of a wider development function, as this would compromise their core planning principles and skills. A number argued further that this situation was often compounded by the role of consultants, who were often in the pay of the major house builders:

[T]here is a tension [...] and it is largely a skills thing, but it [...] partly goes back to what is the consultant actually trying to achieve? Is he actually trying to achieve a sustainable development or is he just trying to achieve a planning permission for his client.

Not surprisingly, many of the planners participating in our on-line forums were involved in a day-to-day struggle to find new ways of overcoming the problems they faced. As we observe below, by examining such practice we begin to understand how networked forms of agency both enable and constrain growth and sustainable development in very particular ways.

\section{Specialist networks and networked agency}

As the research progressed, we observed how individual planners initiated new networks or policy groupings in order to find solutions to the problems they faced. The planners working in this way attempted to enrol and mobilize human and non-human intermediaries into new networks (Callon, 1991) as and when the need arose in order to move the NGP forward. The planners working in this way - whom we termed the hybrid planner (see Crawford, 2004) - were associated with development management functions, as suggested in the online forums, and with the planning of services like schools. While some research participants claimed that hybrid practice had only recently emerged in line with the emergence of the spatial planning agenda (Inch, 2010), the practices involved were not universally recognised as radical or new by all those working in this way. What was clear, however, was the need for these new ways of working to progress the dual task of achieving growth and sustainable development.

An individual performing this role for a District planning authority talked about the wider networks of individuals (from planning directorates, environmental agencies, sustainability consultants and not-for-profit organisations) she had brought together in new policy groupings to find solutions to the problems she faced. The inclusion of 'new' technologies in the NGP had been a recurring theme from the very early days of the planning process, and during the on-line forums many of the issues overseen by the individual were brought up and discussed. One recurring issue revolved around the code for sustainable homes, where planners felt they lacked the knowledge they needed to take the NGP project forward. Another discussion focussed on energy networks and how efficient energy supplies could be secured.

It was in this context that the hybrid planner set up a specialist network, otherwise known as the Renewable Energy Steering Group, to facilitate Section106 negotiations with the developer's consortium. The new policy grouping set out to address the competing visions for sustainability contained in the developer's sustainability strategy and the District planning authority's planning guidance. The contentious issues 
revolved around renewable energy, the code for sustainable homes and the need to reduce carbon emissions (McManus et al., 2010). Initially the District planning authority were asking for, amongst other things, 30 per cent renewable energy and level 5 on the code for sustainable homes. The developer's consortium was extremely resistant to getting anywhere near this and fought hard to dilute the planning guidance. This was not surprising, as the more the consortium addressed the District authority's aspirations for sustainability, the less profit they were likely to make.

For a long time the consortium steadfastly disagreed with anything that went past minimal legal requirements. The network coordinator, who worked for a third sector organisation, highlighted the problems faced by District planners in this instance:

When I became involved [...] my assessment was that the developers were actually very close to wearing down the Local Planning Authority, it was basically the approach that they seemed to be taking was one of a war of attrition and basically a flat no whatever they were asked about.

During 2005 and 2006, the process of negotiation was thus 'Iong and painful' and for many months there was 'a chasm' between what was being asked for by the District and what was being offered by the consortium. Whenever there was a problem during negotiations the consortium would turn to their sustainability consultant, a well-known figure connected to central Government, who would confront District planners with a generic answer along the lines of:

No, can't do it, doesn't work, it's going to cost too much, if you want us to do any of this stuff it means we're going to have to take money off elsewhere, you make the choice, do you want us to spend some money on sustainability or do you want more affordable housing.

In many instances it appeared that the District planning authority did not know whether the answer or information the consultant gave them was right or wrong. This situation further reinforced the power of the developers within the interdependency networks surrounding the NGP whilst lessoning the power of District planners (Elias, 2000; Newton, 2002). The network coordinator claimed that the problems faced by District planners were extenuated by their lack of knowledge, which repeatedly undermined their attempt to enrol and mobilise a range of human and non-human intermediaries into a convergent network (Callon, 1991).

By the time outline planning permission was granted in December 2006 negotiations had progressed a little. Through work with and input from partners from different professional and philosophical backgrounds, the District had managed to get the developers consortium to level 3 on the code for sustainable homes and to 16.4 per cent on renewable energy. This was something of a come down by the consortium, but it was still a long way below the District planner's initial aspirations for the new settlement. Nevertheless, as the hybrid planner pointed out, the specialist network was extremely important in this context, generating new knowledge and moving the overall debate forward:

I've learnt an awful lot recently about energy networks and the mechanisms for securing that, through discussion with energy suppliers, through our work, through planning applications with individual developers, and it's an area where there [...] does seem to be a lack of knowledge and skills and understanding.

We saw earlier how planners involved in the new ways of working evolving around the NGP sometimes had insights in a reactive or intuitive way (Eraut and Hirsh, 2010). This was again the case here, with the dynamics of the group facilitating insights that would not otherwise have been forthcoming. Significantly, it was not just planners who had moments of realisation within these fragile networks. A participant from an 
environmental agency spoke of his realisation, during discussions, that his organisation was wasting their time with individual composting schemes. There was a sudden realisation, he argued, that wildlife corridors were needed across the NGP if it was to be sustainable over the long term.

\section{Reflections of networked agency}

It is clear that these specialist networks enable and constrain individual planners in very particular ways. As we observed, there was a gradual move away from networks converging around established forms of knowledge and practice towards new (fragile) networks and emergent forms of practice. Arguably it was in this context that a range of human and non-human intermediaries helped those involved to translate their strategies in ways that helped them to move forward in their attempt to facilitate the twin tasks of growth and sustainable development. Because of the rise of the spatial planning agenda, there is an assumption that planners will transform the way they work and act as knowledge brokers (Rydin et al., 2007). However, because of the pressures involved, planners have little time to reflect on what they do and they often learn reactively during 'moments' of realization (Eraut and Hirsh 2010). Although the plans and strategies of those involved are rarely implemented as intended (Elias, 2000), established knowledge and practice is nonetheless challenged and redefined as complex networked relations facilitate learning and new ways of doing things (Newton, 2002).

At the end of the project, a number of participants thanked the research team for providing a forum through which they could work through the problems they faced. In much the same way that hybrid planners found specialist networks a good way of finding new solutions to the problems they faced, so our on-line forums provided research participants with a space where they could work together effectively. In an institutional context where there was no predefined knowledge base for the task of developing and building sustainable communities, participants saw great value in the provision of a space where they could discuss their problems and think about developing new forms of knowledge and practice (Scholz et al., 2006). ${ }^{4}$ Elias (1991) argues that the transmission of human knowledge is dependent on a nexus of man made symbols that facilitate communication and orientation. While the overall meaning of sustainability remains highly contested, the symbols of sustainability still allow competing groups to communicate and debate the changing relationship between social, economic and ecological systems. As Feindt and Netherwood (2011: 171) confirm, even 'if the precise meaning of the code or symbol is not consensual, the processes of contested interpretation help to focus societal communication and meaning.'

A participant in an on-line forum confirmed the complexity involved, pointing out how those involved in sustainability work must 'talk... with people from many different perspectives to start to get the connections right.' It follows that any move towards a 'robust sustainability paradigm' (Marsden, 2011) will require increasingly sophisticated ways of bringing competing groups together. By implication, the increasingly complex nature of sustainability work will require increasingly sophisticated methodological approaches and interdisciplinary synthesis (Elias, 1991; Franklin and Blyton, 2011).

\section{Conclusion}

This paper has attempted to demonstrate how an INP challenges the notion of the independent actor on which the knowledge and skills agenda stands. Our main focus in making this argument has been a specialist network emerging around our case study 
NGP. These specialist networks are fragile and uncertain; they often existed for a short period of time, sometimes for a little longer as a means of solving problems individual planners are grappling with. The specialist network we discussed emerged as a response to the concerns of an individual planner, who lacked the skills and knowledge needed to move the NGP forward. The developers consortium involved in the NGP at this time was strongly connected to networks that converged around established carbon based resources and technologies, and they were thus extremely reluctant to commit to newer technologies they had no control over. The power of the consortium was such that they were able to resist, over long periods, the demands placed on them by District planners. It was only through the development of a new policy grouping that a hybrid planner generated insights that enabled District planners to compete with the developer's consortium on equal terms.

From a figurational perspective (Elias, 1970; 1983; 1991; 2000) this is no real surprise. Attempts to bring about change by one group will always be moderated by the interests of other networked groups, each with their own plans, objectives and intentions. However, as we also observed, the demands made by non-human actors of human actors are also increasing in this context (Callon, 1991); keeping up with developments in science and technology is now just as important as keeping up with changes in Government policy. By studying these processes it is clear that we are not only studying the convergence of networks that facilitate growth and sustainable development; we are also studying networks that hinder growth and sustainable development. While relations within interdependency networks may serve to enable social learning, it is clear that they may also help to constrain it (Owen-Pugh, 2007). Our conclusion, therefore, is that it may be more productive to research the minimal levels of interdependency needed to support learning in this context than it is to focus on the acquisition of new knowledge and skills by individual practitioners.

\section{Notes}

1 The ASC is now known as Homes and Communities Academy, which sits within the Homes and Communities Agency (HCA).

2 The text represents the views of the authors and does not necessarily represent the views of the funders; grant number RES-182-25-0021.

3 The on-line groups used Schön's (1983) 'reflective learning cycle' to examine tensions between established groups of planners and new ways of working.

${ }^{4}$ One of the authors has discussed the impact of participation in collaborative spaces elsewhere (Taylor et al., 2009; Taylor, Howard and Lever, 2010; Howard and Lever, 2011)

\section{Acknowledgments}

We would like to thank the anonymous reviewer who provided useful and insightful comments.

* Correspondence Address: John Lever, Huddersfield University Business School. Email: j.b.lever@hud.ac.uk. 


\section{Bibliography}

ASC (2007) Mind the Skills Gap: The skills we need for sustainable communities. Academy for Sustainable Communities.

Callon, M. (1986) Some elements of a sociology of translation: domestication of the scallops and the fishermen of St Brieuc Bay. In: John Law (ed.), Power, Action and Belief: A New Sociology of Knowledge? London: Routledge and Kegan Paul.

Callon, M. (1986a) The sociology of an actor-network: The case of the electric vehicle. In: Michel Callon, John Law and Arie Rip (eds.), Mapping the Dynamics of Science and Technology: Sociology of Science in the Real World. Basingstoke: Macmillan.

Callon, M. (1991) Techno-economic networks and irreversibility. In: John Law (ed.), A Sociology of Monsters? Essays on Power, Technology and Domination, Sociological Review Monograph 38. London: Routledge.

Crawford, J. (2009) Values, networking and the hybrid planner. Planning Theory and Practice, 10, 2, 161-164.

Cullingworth, B. and Nadin, V. (2006) Town and Country Planning in the UK. London: Routledge, 14th Edition.

DCLG (2007) Homes for the future: more affordable, more sustainable. London: Department for Communities and Local Government.

DCLG (2008) New Growth Points Initiative: Partnership for Growth and Government. London: Department for Communities and Local Government.

Egan, J. (2004) The Egan Review: Skills for Sustainable Communities. London: Office of the Deputy Prime Minister.

Elias, N. (1970) What is Sociology? New York: Columbia University Press.

Elias, N. (1983) The Court Society. Oxford: Basil Blackwell.

Elias, N. (1991) The Symbol Theory. London: Sage.

Elias, N. (2000: first published in 1939) The Civilizing Process, Sociogenetic and Psychogenetic Investigations. Oxford: Basil Blackwell.

Engeström, Y. (2001) Expansive learning at work: towards an activity theoretical reconceptualisation. Journal of Education and Work, 14, 1, 133-156.

Eraut, M. (2004) Informal learning in the workplace. Studies in Continuing Education, 26, 2.

Eraut, M. and Hirsh, W. (2010) The Significance of Workplace Learning for Individuals, Groups and Organisations, Monograph. http://www.skope.ox.ac.uk/sites/default/files/Monogrpah\%209.pdf

Feindt, P.H. and Netherwood, A. (2011) Making Sense of Climate Change: Notes on Interpretative Policy Analysis and Discourse Analysis in Sustainability Research. In: Franklin, A. and Blyton. P. (2011) Researching Sustainability: A Guide to Social Science Methods, Practice and Engagement. London: Routledge.

Franklin, A. and Blyton. P. (2011) Researching Sustainability: A Guide to Social Science Methods, Practice and Engagement. London: Routledge.

Howard, J. and Lever, J. (2011) 'New Governance Spaces': what generates a participatory disposition in different contexts? Voluntary Sector Review, 2, 1.

Inch. A. (2010) Culture change as identity regulation: the complex politics of producing spatial planners in England. Planning Theory and Practice, 11, 3, 359-374.

Karadimitriou, N. (2013) Planning policy, sustainability and housebuilder practices: The move into (and out of?) the redevelopment of previously developed land. Progress in Planning, 82, 1-41.

Lever, J. (2010) Urban Regeneration Partnerships: a figurational critique of governmentality theory. Sociology, 45, 1.

Marsden, T. (2011) Sustainability Science and a New Spatial Imagination: Exploring Some Analytical And Methodological Considerations. In: Franklin, A. and Blyton. P. (2011) Researching Sustainability: A Guide to Social Science Methods, Practice and Engagement. London: Routledge. 
Marsden, T., Franklin, A., Newton, J. and Middleton, J. (2010) Sustainability in practice: situated learning and knowledge for the evolving eco-economy. Town Planning Review, 81, 5.

McManus, A., Gaterell, M.R. and Coates, L.E. (2010) The potential of the Code for Sustainable Homes to deliver genuine 'sustainable energy' in the UK social housing sector. Energy Policy, 38, 4, 2013-2019.

Murdoch, J. (2001) Ecologising Sociology: Actor-Network Theory, Co-construction and the Problem of Human Exemptionalism. Sociology, 35, 1, 111-133.

Newman, J. (2001) Modernising Governance: New Labour, Policy and Society. London: Sage Publications.

Newton, T. (1996) Agency and discourse: Recruiting consultants in a life insurance Company. Sociology, 30, 4, 717-739.

Newton, T. (2001) Creating the New Ecological Order? Elias and Actor Network Theory. In: Van Iterson, A., Mastenbroek, M., Newton, T., and Smith, D., (2002) (eds.) The Civilized Organization: Norbert Elias and the future of organization studies. Amsterdam: John Benjamins Publishing Co.

Newton, T. (2007) Nature and Sociology. London: Routledge.

ODPM (2003) Sustainable Communities: Building for the Future. London: Office of the Deputy Prime Minister/HMSO.

Owen-Pugh, V. (2007) Sport as a Community of Practice: The Coach-Athlete Relationship in British Professional Basketball. In: Hughes, J., Jewson, N. and Unwin, L., (eds) Communities of Practice: Critical Perspectives. London: Routledge.

Raco, M. (2005) Sustainable Development, Rolled-out Neo liberalism and Sustainable Communities. Antipode, 37, 2, 324-347.

Richards, S. (2007) Richards on...delivering for communities. Planning (September), p. 14.

RTPI (2007) Shaping and Delivering Tomorrow's Places: Effective Practice in Spatial Planning. London: RTPI.

Rydin, Y., Amjad, U. and Whitaker, M. (2007) Environmentally sustainable construction: knowledge and learning in London planning departments. Planning Theory and Practice, 8, 3, 363-380.

Scholz, R.W., Lang, D.J., Wiek, A., Walter, A. I. and Stauffacher, M. (2006) Transdisciplinary case studies as a means of sustainability learning: Historical framework and theory, International Journal of Sustainability in Higher Education, 7, 3, 226-251.

Sehested, K. (2009) Urban planners as network managers and metagovernors. Planning Theory and Practice, 10, 2, 245-263.

Schön, D. (1983) The Reflective Practitioner, How Professionals Think In Action. Basic Books.

Smith, I. (2008) Situated social learning and the management of urban growth: Delivering new growth points in England. Presentation to EURA conference, Milan, October 2008.

Smith, I. (2009) The work of learning in communities of practice: planners reflecting on their everyday collaborative work. Presentation to Annual Planning Research Conference, University of Newcastle, April 2009.

Tait, M. (2002) Room for manoeuvre? An actor-network study of central-local relations in development plan making. Planning Theory and Practice, 3, 1, 69-85.

Taylor, M., Howard, J., Harris, V., Lever, J., Mateeva, A., Miller, C., Petrov, R. and Serra, L. (2009) Dilemmas of engagement: the experience of non-governmental actors in new governance spaces. NGPA Research Paper 31.

Taylor, M., Howard, J. and Lever, J. (2010) Citizen Participation and Civic Activism in Comparative Perspective. The Journal of Civil Society, 6, 2. 
p. 126. Learning to build sustainable communities: an interdependency network perspective

Tewdwr-Jones, M. (2004) Spatial Planning: Principles, Practices and Cultures. Journal of Planning and Environment Law, 31 (May), 560-569.

Vygotsky, L. (1978) Mind in Society: the development of higher psychological processes. Cambridge: Harvard University Press. 